\title{
Five-year period of evaluation of leaf mineral concentrations in resistant varieties in Trentino (Northeastern Italy)
}

\author{
Duilio Porro ${ }^{1 *}$, Daniela Bertoldi ${ }^{1}$, Maurizio Bottura ${ }^{1}$ and Stefano Pedò ${ }^{1}$ \\ ${ }^{1}$ Technology Transfer Centre, Edmund Mach Foundation, via E. Mach 1, 38010 San Michele all'Adige, Italy
}

\begin{abstract}
Recently new resistant and/or tolerant genotypes to the main cryptogams (downy and powdery mildew) were identified, to be used in enhancing sustainable viticulture. These cultivars (result of interspecific crossings between Vitis vinifera cultivars and other Vitis species of American and Asian origin) are experiencing a relevant expansion in Europe in viticultural regions characterized by high rainfall per year. In two sites of Trentino (Northeastern Italy) with different soil pH levels, and where these conditions are widespread, an important study was scheduled. During the period 2015-2019, fifteen resistant varieties were monitored in order to have information about agronomical and nutritional behavior. Yearly, at fruit set nutritional aspects through leaf analyses and leaf green color (SPAD indexes) were monitored. At pre-veraison, photosynthetically active biomass behavior (Normalized Difference Vegetation Index - NDVI indexes) was controlled. Weather conditions of different years strongly changed the availability of nutrients in vines in relation to different genotypes and their color of vegetation and vigor. Collected results allow to suggest interventions aimed at a more suitable nutritional management for resistant varieties, in comparison of Vitis vinifera, above all for nitrogen $(\mathrm{N})$, potassium $(\mathrm{K})$, and zinc $(\mathrm{Zn})$; in particular, for magnesium $(\mathrm{Mg})$, early foliar treatments should be recommended, especially in years where rainfall is concentrated in the spring months.
\end{abstract}

\section{Introduction}

Cultivars that have disease resistant traits (result of obtained interspecific crossings between Vitis vinifera cultivars and other Vitis species of American and Asian origin) require during the growing season a lower number of treatments to control both downy mildew (Plasmopara viticola) and powdery mildew (Erysiphe necator) in comparison with Vitis vinifera cultivars. The introduction of grapevine cultivars less susceptible to diseases, with a low impact on the environment, had a relevant expansion in Europe in the last few years in viticultural regions characterized by high rainfall levels per year, requiring several fungicide applications.

In Trentino viticultural region, these conditions exceed an average of $800-900 \mathrm{~mm}$ precipitation per year, and therefore the possibility to use resistant and or tolerant varieties registered in the Italian catalog of wine varieties, even if these are not allowed for wines with a designation of origin, has been seen as a real option for grape producers to enhance sustainable viticulture by reducing the number of plant protection treatments.

In the last few years several hectares cultivated with these cultivars were planted in Trentino with the aim to obtain information on agronomical and physiological aspects. Currently, little information is available on the nutritional requirements of these cultivars, with previous work based on a shorter period of observation [1, 2], indicating particular attention for $\mathrm{Mg}$ management.
The aim of this work focused on the evaluation of the nutrient status of some resistant varieties, in order to confirm previous results and suggest to the viticulturist an enhanced fertilizer management program.

\section{Materials and methods}

In two different sites of Trentino, Telve $\left(46^{\circ} 03^{\prime} 34.01^{\prime \prime} \mathrm{N}\right.$, $11^{\circ} 28^{\circ} 39.27^{\prime \prime E}$; altitude $440 \mathrm{~m}$ a.s.l.) and Rovereto (46 $52^{\circ} 37.96 " \mathrm{~N}, 11^{\circ} 01^{\prime} 14.03 " \mathrm{E}$; altitude $220 \mathrm{~m}$ a.s.l.), in vineyards representing the widespread soil conditions of viticultural area (sandy-loam soils), fifteen different genotypes of grapevine resistant/tolerant to the main fungal diseases were tested, by monitoring during the 2015-2019 period, agronomical and nutritional behavior. Seven white berry varieties (Aromera, Bronner, Helios, Johanniter, Muscaris, Solaris and Souvignier gris) and eight red berry varieties (Baron, Cabernet Cantor, Cabernet Cortis, Cabernet Carbon, Cabino, Monarch, Prior, and Regent) were used. The most part of these genotypes - except Aromera, Baron, Cabernet Cantor, and Cabino - are registered in the Italian catalog of wine varieties and their cultivation is allowed in Trentino.

The location of Telve was on alpine fluvial conoid, characterized by acid $\mathrm{pH}$, with high organic content $(4.1 \%)$, and very rich in phosphorus and magnesium, high potassium availability, balanced $\mathrm{Mg} / \mathrm{K}$ ratio, and good cation exchange capacity. The vines were trained to Guyot. The location of Rovereto was on an alluvial

\footnotetext{
* Corresponding author: duilio.porro@fmach.it
} 
plain, sub-alkaline, extremely calcareous soil, characterized by good level of active limestone $(3.8 \%)$ and organic matter $(2.3 \%)$. High availability of phosphorus and magnesium, medium content in potassium, high $\mathrm{Mg} / \mathrm{K}$ ratio, and low cation exchange capacity characterized this soil. Vines were trained to simple pergola. Both vineyards were planted in 2013 utilizing for the most part of varieties the rootstock SO4. Aromera, Cabino, Muscaris and Souvignier gris were instead planted respectively on rootstock 1103 Paulsen, 101-14 Millardet, and Kober 5 BB (the last two). Considering the importance of the rootstock in the nutritional behavior, for a correct evaluation, in the present paper only the varieties grafted on SO4 were considered.

In both locations soil fertilization was conducted yearly supplying a low amount of $\mathrm{N}, \mathrm{P}_{2} \mathrm{O}_{5}$ and $\mathrm{K}_{2} \mathrm{O}$, respectively of 30,6 , and $40 \mathrm{~kg} / \mathrm{ha}$. Both vineyards are covered with grass. During the first three years of observation no antifungal treatments were carried out to protect the vines, whilst in the following years, 2-3 treatments were done.

During the five years period of evaluation (20152019), year was used as a replication, due to the fact that in each location the fifteen genotypes were not replicated, being in single plots of fifteen vines. SPAD and NDVI levels, as well as leaf mineral nutrient status were measured each year from 2015 to 2019. SPAD was quantified by using a Minolta SPAD-502 leaf chlorophyll meter (Minolta Camera Co., Osaka, Japan) at fruit-set, collecting 30 readings/plot (2 leaves/vine) on the leaf opposite to the first cluster in the terminal region of the leaf. At this phenological stage, the same leaves used for SPAD analysis were collected for mineral determinations. All samples were washed, oven-dried, ground, and analyzed for $\mathrm{N}$, phosphorus $(\mathrm{P}), \mathrm{K}$, calcium $(\mathrm{Ca}), \mathrm{Mg}$, iron $(\mathrm{Fe})$, manganese $(\mathrm{Mn})$, boron $(\mathrm{B})$, cupper $(\mathrm{Cu}), \mathrm{Zn}$, and sulfur $(\mathrm{S})$ composition. $\mathrm{N}$ was determined by the Dumas total combustion method and the other elements concentration by plasma emission spectroscopy following acid digestion [3].

Assessments of biomass photosynthetically active (vigor of trees) were obtained by using SkyeSpectrosense 2+ (Skye Instruments Ltd, Powys, UK) able to give NDVI values in pre-veraison (July), collecting for all the vines of the plot 15 measurements. The NDVI compares red and near infrared spectral reflectance of the canopy, with high values indicating greater vigor.

The effects of year, site, and cultivar were evaluated by analysis of variance (ANOVA). All data were statistically processed using Systat software package (Systat Software, California, USA). Mean separation was done using the Tukey test. In order to correctly "weight" the effect of variety, data were standardized (mean equal 0 and standard deviation equal 1) by year and site. The multivariate procedure of Cluster Analysis was applied to the standardized mean values of some parameters with the aim to grouping the different resistant varieties from a nutritional point of view. Normalized Euclidean distances (root mean-squared distances) were used.

\section{Results and discussion}

All the studied parameters showed great variability between years, sites, and cultivars. Data related to year effect are not shown. Nevertheless, it is important to report that year effect strongly affected levels of both SPAD and NDVI, as well as the concentrations in leaves of $\mathrm{N}, \mathrm{P}, \mathrm{K}, \mathrm{Mg}, \mathrm{S}, \mathrm{Fe}, \mathrm{B}, \mathrm{Cu}$, and $\mathrm{Zn}$. In particular, the availability and the uptake by the vines of the three cations $\mathrm{K}, \mathrm{Ca}$, and $\mathrm{Mg}$ seemed to be depending on rainfall registered in springtime (March, April, Maj and June). The highest $\mathrm{K}$ concentrations in leaves in both sites - values respectively of $1.25 \%$ dry matter - d.m. at Rovereto and of $1.15 \%$ d.m. at Telve - were registered in the year 2018 characterized by the highest levels of rainfall in spring (table 1), when the lowest concentrations in leaves of $\mathrm{Mg}(0.19$ and $0.16 \%$ d.m. respectively at Rovereto and at Telve) and $\mathrm{Ca}(2.30 \%$ and $1.18 \%$ d.m. at Rovereto and at Telve) were found.

Table 1. Weather trend of mean temperature (MT) and rainfall recorded in spring in the two locations in relation to the years.

\begin{tabular}{ccccc}
\hline \multirow{2}{*}{ Year } & \multicolumn{2}{c}{ Telve } & \multicolumn{2}{c}{ Rovereto } \\
\cline { 2 - 5 } & $\begin{array}{c}\text { MT } \\
{ }^{\circ} \mathrm{C}\end{array}$ & $\begin{array}{c}\text { Rainfall } \\
\mathrm{mm}\end{array}$ & $\begin{array}{c}\text { MT } \\
{ }^{\circ} \mathrm{C}\end{array}$ & $\begin{array}{c}\text { Rainfall } \\
\mathrm{mm}\end{array}$ \\
\hline 2015 & 14.00 & 257.2 & 16.25 & 172.8 \\
2016 & 13.42 & 338.6 & 15.32 & 335.0 \\
2017 & 14.90 & 316.6 & 16.62 & 397.6 \\
2018 & 13.82 & 456.0 & 15.20 & 516.2 \\
2019 & 13.98 & 482.0 & 15.43 & 320.8 \\
\hline
\end{tabular}

The site of Telve (table 2), characterized by acid $\mathrm{pH}$ of soil, increased $\mathrm{Fe}, \mathrm{Mn}$, and $\mathrm{Zn}$ leaf concentration, while decreased the uptake of $\mathrm{P}, \mathrm{K}$, and $\mathrm{Ca}$ in confront of the site of Rovereto (table 3 ). These results confirmed that most of micronutrients ( $\mathrm{Fe}, \mathrm{Mn}$, and $\mathrm{Zn}$ ) tend to be more available when soil $\mathrm{pH}$ is low, whilst the absorption of cations $(\mathrm{K}, \mathrm{Ca}$, and $\mathrm{Mg}$ ) is better in alkaline soils [4].

Resistant varieties presented great and significant differences among them for the most part of investigated parameters. This was true for the site of Telve (table 2) where significant differences were found for SPAD, NDVI, K, P, Ca, Fe, Mn, and Zn; in the site of Rovereto (table 3) differences among varieties regarded SPAD, NDVI, N, K, Ca, Mg, B, and Zn. In both sites cultivar effect did not affect $\mathrm{S}$ and $\mathrm{Cu}$ leaf nutrient concentrations. It is not easy to describe the differences due to variety. However, during the period of observation, it was registered that elements $\mathrm{N}, \mathrm{K}, \mathrm{Mg}$, $\mathrm{Fe}, \mathrm{Mn}$, and $\mathrm{Zn}$ revealed critical leaf values (deficiencies) in some years in relation to the site and to the cultivar, according to the reference values considered [5]. Mean values reported in tables indicated that in both sites Bronner, Prior, Solaris, and Regent (only at Telve) 
showed the lowest SPAD levels, but had not the lowest values of vigor and absorption of $\mathrm{N}$. These results put in evidence that the vigor of the plant, the color of vegetation, and availability of $\mathrm{N}$ and other elements in plants are not directly linked. Regent, Johanniter, Baron, and Cabernet Carbon showed significant (at Rovereto) higher $\mathrm{N}$ levels in leaves in confront of Solaris that presented the lowest $\mathrm{N}$ uptake. A similar behavior was observed at Telve, although without statistical significance.
Bronner in both sites had significant higher $\mathrm{K}$ concentrations in leaves than Solaris, who revealed K deficiencies, similarly to those observed in Prior and Johanniter at Telve, and in Cabernet Cortis at Rovereto as yellowing or reddening of marginal part of limb of older leaves; in extreme cases symptoms became necrosis.

Table 2. Mean values of SPAD and NDVI indexes, and of some mineral concentration in leaves in relation to the cultivar at Telve. For SPAD, 1650 cases; for NDVI, 825 cases; for each nutritional parameter, 55 cases.

\begin{tabular}{|c|c|c|c|c|c|c|c|c|c|c|c|}
\hline \multirow{2}{*}{ Cultivar } & \multirow{2}{*}{ SPAD } & \multirow{2}{*}{ NDVI } & \multicolumn{9}{|c|}{ Nutrient concentration in leaves $\left({ }^{1} \%\right.$ or ${ }^{2} \mathrm{mg} / \mathrm{kg}$ d.m.) } \\
\hline & & & ${ }^{1} \mathbf{N}$ & ${ }^{1} \mathbf{P}$ & ${ }^{1} \mathbf{K}$ & ${ }^{1} \mathbf{C a}$ & ${ }^{1} \mathbf{M g}$ & ${ }^{2} \mathbf{F e}$ & ${ }^{2} \mathbf{M n}$ & ${ }^{2} \mathbf{B}$ & ${ }^{2} \mathbf{Z n}$ \\
\hline Baron & $39.5 \mathrm{a}$ & $0.66 \mathrm{ab}$ & 2.65 & $0.20 \mathrm{a}$ & $0.95 \mathrm{ab}$ & $1.96 \mathrm{a}$ & 0.26 & $105 a b$ & $180 \mathrm{ab}$ & 24 & $27 \mathrm{ab}$ \\
\hline Bronner & 31.5 bcde & $0.57 \mathrm{abc}$ & 2.31 & $0.15 \mathrm{~b}$ & $1.21 \mathrm{a}$ & $1.24 \mathrm{~b}$ & 0.17 & $93 \mathrm{~b}$ & $126 \mathrm{bc}$ & 20 & $18 \mathrm{c}$ \\
\hline C.Cantor & $32.1 \mathrm{bcd}$ & $0.57 \mathrm{bc}$ & 2.38 & $0.16 \mathrm{~b}$ & $0.94 \mathrm{ab}$ & $1.18 \mathrm{~b}$ & 0.21 & $109 a b$ & $110 \mathrm{c}$ & 17 & $23 a b c$ \\
\hline C.Carbon & $37.1 \mathrm{ab}$ & $0.69 \mathrm{a}$ & 2.55 & $0.19 \mathrm{ab}$ & $1.23 \mathrm{a}$ & $1.45 \mathrm{ab}$ & 0.22 & $94 \mathrm{ab}$ & $189 \mathrm{a}$ & 22 & $22 a b c$ \\
\hline C.Cortis & $26.3 \mathrm{e}$ & $0.53 \mathrm{c}$ & 2.30 & $0.16 \mathrm{~b}$ & $0.97 \mathrm{ab}$ & $1.07 \mathrm{~b}$ & 0.23 & $92 \mathrm{~b}$ & $113 \mathrm{c}$ & 17 & $31 \mathrm{a}$ \\
\hline Helios & 30.6 cde & $0.56 \mathrm{bc}$ & 2.51 & $0.17 \mathrm{ab}$ & $1.00 \mathrm{ab}$ & $1.09 \mathrm{~b}$ & 0.23 & $97 \mathrm{ab}$ & $110 \mathrm{c}$ & 15 & $26 a b c$ \\
\hline Johanniter & $35.8 \mathrm{abc}$ & $0.60 \mathrm{abc}$ & 2.92 & $0.17 \mathrm{ab}$ & $0.91 \mathrm{~b}$ & $1.58 \mathrm{ab}$ & 0.19 & $125 \mathrm{ab}$ & $150 \mathrm{ab}$ & 19 & $22 \mathrm{abc}$ \\
\hline Monarch & $35.1 \mathrm{abcd}$ & $0.61 \mathrm{abc}$ & 2.27 & $0.18 \mathrm{ab}$ & $0.95 \mathrm{ab}$ & $1.44 \mathrm{ab}$ & 0.19 & $106 a b$ & $143 \mathrm{ab}$ & 19 & $18 \mathrm{c}$ \\
\hline Prior & $29.3 \mathrm{de}$ & $0.58 \mathrm{abc}$ & 2.34 & $0.15 \mathrm{~b}$ & $0.91 \mathrm{~b}$ & $1.39 \mathrm{ab}$ & 0.22 & $111 \mathrm{ab}$ & $122 \mathrm{bc}$ & 16 & $21 \mathrm{bc}$ \\
\hline Regent & $29.0 \mathrm{e}$ & $0.61 \mathrm{abc}$ & 2.79 & $0.21 \mathrm{a}$ & $1.29 \mathrm{a}$ & $1.43 \mathrm{ab}$ & 0.20 & $127 \mathrm{a}$ & $171 \mathrm{ab}$ & 19 & $22 \mathrm{abc}$ \\
\hline Solaris & $29.9 \mathrm{de}$ & $0.64 a b c$ & 2.24 & $0.15 \mathrm{~b}$ & $0.92 \mathrm{~b}$ & $1.51 \mathrm{ab}$ & 0.25 & $100 \mathrm{ab}$ & $150 \mathrm{ab}$ & 19 & $18 \mathrm{bc}$ \\
\hline Signific. & $* * *$ & $* *$ & n.s. & $* * *$ & $*$ & $* * *$ & n.s. & $* *$ & $* * *$ & n.s. & $* * *$ \\
\hline
\end{tabular}

Within-rows mean values followed by different letters are significantly different by Tukey test. Level of significance: n.s. $=\quad$ not $\quad$ significant; $* \quad=$ significance for $\mathrm{p} \leq 0.050$ and $\mathrm{p} \geq 0.010 ; * *=$ significance for $\mathrm{p}<0.010$ and $\mathrm{p} \geq 0.001 ; * * *=$ significance for $\mathrm{p}<0.001$.

Table 3. Mean values of SPAD and NDVI indexes, and of some mineral concentration in leaves in relation to the cultivar at Rovereto. For SPAD, 1650 cases; for NDVI, 825 cases; for each nutritional parameter, 55 cases.

\begin{tabular}{|c|c|c|c|c|c|c|c|c|c|c|c|}
\hline \multirow{2}{*}{ Cultivar } & \multirow{2}{*}{ SPAD } & \multirow{2}{*}{ NDVI } & \multicolumn{9}{|c|}{ Nutrient concentration in leaves ( $1 \%$ or ${ }^{2} \mathrm{mg} / \mathbf{k g}$ d.m.) } \\
\hline & & & ${ }^{1} \mathbf{N}$ & ${ }^{1} \mathbf{P}$ & ${ }^{1} \mathbf{K}$ & ${ }^{1} \mathbf{C a}$ & ${ }^{1} \mathrm{Mg}$ & ${ }^{2} \mathbf{F e}$ & ${ }^{2} \mathrm{Mn}$ & ${ }^{2} \mathbf{B}$ & ${ }^{2} \mathbf{Z n}$ \\
\hline Baron & $39.4 \mathrm{a}$ & $0.69 \mathrm{a}$ & $2.72 \mathrm{ab}$ & 0.21 & $1.20 \mathrm{bc}$ & $2.73 \mathrm{ab}$ & $0.22 \mathrm{ab}$ & 80 & 22 & $27 \mathrm{cde}$ & $24 \mathrm{ab}$ \\
\hline Bronner & $29.3 \mathrm{~cd}$ & $0.66 \mathrm{a}$ & $2.47 \mathrm{bc}$ & 0.20 & $1.63 \mathrm{a}$ & $2.42 \mathrm{ab}$ & $0.18 b$ & 75 & 26 & $48 \mathrm{ab}$ & $17 \mathrm{~b}$ \\
\hline C.Cantor & $32.1 \mathrm{bcd}$ & $0.62 \mathrm{ab}$ & $2.40 \mathrm{bc}$ & 0.18 & $1.20 \mathrm{bc}$ & $2.42 \mathrm{ab}$ & $0.25 \mathrm{ab}$ & 90 & 21 & $45 \mathrm{abc}$ & $23 \mathrm{ab}$ \\
\hline C.Carbon & $37.6 \mathrm{ab}$ & $0.69 \mathrm{a}$ & $2.70 \mathrm{ab}$ & 0.24 & $1.36 \mathrm{ab}$ & $2.51 \mathrm{ab}$ & $0.24 \mathrm{ab}$ & 69 & 27 & $51 \mathrm{ab}$ & $21 \mathrm{ab}$ \\
\hline C.Cortis & $28.0 \mathrm{~cd}$ & $0.64 \mathrm{ab}$ & $2.36 \mathrm{bc}$ & 0.19 & $0.94 \mathrm{c}$ & $2.58 \mathrm{ab}$ & $0.31 \mathrm{a}$ & 79 & 28 & $58 \mathrm{a}$ & $26 \mathrm{a}$ \\
\hline Helios & $27.8 \mathrm{~cd}$ & $0.58 \mathrm{~b}$ & $2.47 \mathrm{bc}$ & 0.23 & $1.20 \mathrm{bc}$ & $1.91 \mathrm{~b}$ & $0.21 \mathrm{ab}$ & 70 & 22 & $29 \mathrm{cde}$ & $24 \mathrm{ab}$ \\
\hline Johanniter & $31.2 \mathrm{bcd}$ & $0.60 \mathrm{ab}$ & $2.70 \mathrm{ab}$ & 0.21 & $1.24 \mathrm{abc}$ & $2.65 \mathrm{ab}$ & $0.20 \mathrm{~b}$ & 89 & 24 & 39 bcd & $23 \mathrm{ab}$ \\
\hline Monarch & $30.4 \mathrm{~cd}$ & $0.65 \mathrm{ab}$ & $2.37 \mathrm{bc}$ & 0.22 & $1.51 \mathrm{ab}$ & $2.51 \mathrm{ab}$ & $0.20 \mathrm{~b}$ & 71 & 23 & $43 \mathrm{bcd}$ & $17 \mathrm{~b}$ \\
\hline Prior & $25.6 \mathrm{~d}$ & $0.59 \mathrm{~b}$ & $2.44 \mathrm{bc}$ & 0.19 & $1.28 \mathrm{abc}$ & $2.02 \mathrm{ab}$ & $0.23 \mathrm{ab}$ & 76 & 17 & $24 \mathrm{de}$ & $25 \mathrm{ab}$ \\
\hline Regent & $34.0 \mathrm{abc}$ & $0.56 \mathrm{~b}$ & $3.03 \mathrm{a}$ & 0.26 & $1.42 \mathrm{ab}$ & $2.53 \mathrm{ab}$ & $0.19 \mathrm{~b}$ & 92 & 31 & $23 \mathrm{e}$ & $18 \mathrm{ab}$ \\
\hline Solaris & $27.4 \mathrm{~cd}$ & $0.69 \mathrm{a}$ & $2.07 \mathrm{c}$ & 0.22 & $1.12 \mathrm{bc}$ & $2.80 \mathrm{a}$ & $0.27 \mathrm{ab}$ & 83 & 32 & $38 \mathrm{bcd}$ & $19 \mathrm{ab}$ \\
\hline Signific. & $* * *$ & $* *$ & $* * *$ & n.S. & $* * *$ & $*$ & $*$ & n.S. & n.s. & $* * *$ & $* *$ \\
\hline
\end{tabular}

Within-rows mean values followed by different letters are significantly different by Tukey test. Level of significance: $\mathrm{n} . \mathrm{s} .=$ not significant; $*$ = significance for $\mathrm{p} \leq 0.050$ and $\mathrm{p} \geq 0.010 ; * *=$ significance for $\mathrm{p}<0.010$ and $\mathrm{p} \geq 0.001 ; * * *=$ significance for $\mathrm{p}<0.001$.

The high availability of $\mathrm{K}$ in Bronner strongly depressed $\mathrm{Mg}$ uptake, as results reported indicate with significant low values of $\mathrm{Mg}$. During the five years period, $\mathrm{Mg}$ deficiencies (yellowing or reddening between veins in the older leaves) were frequently observed and confirmed by visual symptoms in 
Johanniter, Monarch, and Regent. These varieties had also low Mg uptake in both sites.

Iron, and boron differences recorded in leaf concentrations among resistant varieties did not appear relevant from an agronomical point of view. In fact, no deficiencies were observed for $\mathrm{Fe}$ and $\mathrm{B}$, due to the fact that no value fell down the references indicated for the concentrations of these nutrients in the leaves.

About $\mathrm{Zn}$, it is important to note that Bronner and Monarch had the lowest concentration in leaves in both sites. These critical values revealed interveinal chlorosis with light mosaic and were visually observed.

However, prevailing environmental conditions, soil properties, and growth dynamics may restrict nutrient uptake and induce deficiencies in vines even if soil nutrient levels are deemed sufficient for optimum yield and quality. Independently from the site, and from the year, these specific deficiencies in some resistant varieties, confirmed by visual symptoms too, should be considered.

In order to obtain precise information of each variety, independently from site of cultivation and year (environmental conditions), data were normalized to compare the relative differences among the cultivars, as reported in material and methods.

The SPAD, NDVI, and leaf analytical data of N, K, $\mathrm{Mg}$, and $\mathrm{Zn}$ were standardized across years and sites by setting the mean equal to 0 and the standard deviation equal to 1. The utilization of Cluster Analysis on data arranged in this way, allowed to get summarized information grouping the varieties for a nutritional point of view.

Some information can be directly taken from tables 2 and 3 and discussion previous done, but an important key of interpretation, may be utilized with success to manage the resistant varieties differently from a nutritional point of view (Figure 1). Grouping of the cultivars in relation to standardized means of SPAD, NDVI and leaf concentration of $\mathrm{N}, \mathrm{K}, \mathrm{Mg}$, and $\mathrm{Zn}$ through Cluster Analysis separated different groups.

Solaris was separated from Cabernet Cortis for the vigor of vegetation, respectively medium high and very low. Both varieties, however, were characterized by very light leaf greenness, the lowest $\mathrm{N}$ and $\mathrm{K}$ uptake associated to the highest $\mathrm{Mg}$ absorption. Further, Solaris had the lowest values of leaf zinc content, whist Cabernet Cortis the opposite.

Helios, Prior, and Cabernet Cantor were grouped: they had the lowest values of NDVI and SPAD associated to a medium concentration of $\mathrm{N}, \mathrm{K}, \mathrm{Mg}$, and $\mathrm{Zn}$ in leaves.

Monarch and Bronner were joined for their lowest $\mathrm{Mg}$ uptake and were put near Johanniter (low Mg, high N, and medium $\mathrm{K}$ ) from one hand and from the other hand near Regent (low Mg, high N, and high K).

Cabernet Carbon, and Baron, that showed the highest levels of vigor associated with greener leaves, rich in $\mathrm{N}$, medium-high levels of $\mathrm{K}, \mathrm{Mg}$, and $\mathrm{Zn}$, were grouped and put at the extreme positions of the Cluster.
Fig. 1. Grouping of the cultivars in relation to standardized means of SPAD, NDVI, and leaf concentration of $\mathrm{N}, \mathrm{K}, \mathrm{Mg}$, and $\mathrm{Zn}$ trough Cluster Analysis.

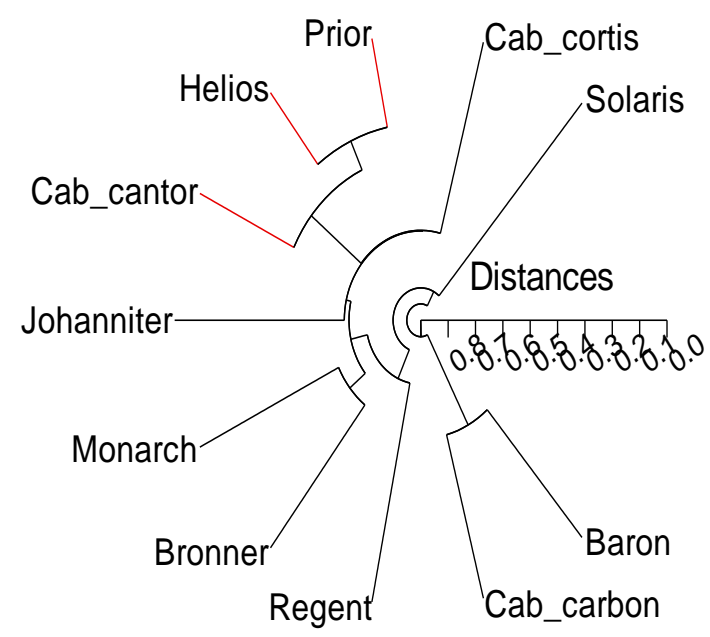

\section{Conclusions}

Data recorded in this study, can allow suggesting to the farmer interventions aimed at a more suitable nutritional management for resistant varieties in comparison with Vitis vinifera.

These varieties need to be monitored with care in confront to traditional varieties cultivated. The result is further strengthened by some observations and indications obtained by research work done at Edmund Mach Foundation studying new resistant varieties.

The obtained new crossings Bianca $x$ Teroldego, Solaris x Regent, Poli Muskotali x Armenia, Merzling $x$ Marzemino, and Marzemino x Merzling, actually under observation before registration in the Italian catalog of wines varieties, revealed deficiencies related to $\mathrm{Zn}, \mathrm{Mn}$, $\mathrm{Mg}$, and $\mathrm{K}$.

Because more equilibrated and productive vines are able to get a good absorption of nutrients and avoid nutritional deficiencies, guaranteeing high quality, it becomes very important the control of nutritional status of these resistant varieties, by leaf analysis, calibrating specific interventions yearly and in relation to different kind of soil. In fact, a good presence of mineral elements in the leaves reflects the optimal uptake by plants from the soil. Grapevine nutrient status must be "verified" based on the vegetative-productive balance over the years and in relation to the soil. Low or high soil $\mathrm{pH}$, soil compaction, and excessively wet or dry soil may restrict nutrient uptake. In fact, dry situations can cause a risk of limited N, P and $\mathrm{K}$ uptake, while under wet conditions $\mathrm{Mg}, \mathrm{Mn}$ and $\mathrm{Zn}$ uptake is more reduced. Mn deficiency occurs more frequency in sandy loam soils, while grapevines growing in sandy loam and silty loam soils are more sensitive to $\mathrm{Zn}$ deficiency. 
Information regarding the main production results ( $\mathrm{kg} / \mathrm{vine}$ and sugar content), the real effective vigor (Ravaz index and number of leaf layers), and the nutrient status of leaves confirmed at Rovereto [2] that Regent and Baron, characterized by high $\mathrm{N}$ levels in leaves, presented excessive vigor, low yield, and medium-low sugar, whilst Cabernet Cantor and Cabernet Cortis, characterized by medium content of $\mathrm{N}$ in leaves, had poor vigor and high sugar. Helios, and Prior presented poor vigor, medium-low $\mathrm{N}$, and low sugar content. It is interesting to note that Monarch, that had low $\mathrm{N}$ availability associated to the highest levels of yield and vigor, was not able to reach the satisfactory amount of sugar content over the years.

On the basis of these results, it possible to put in evidence that a careful agronomical handling of fertilization and canopy management may reduce such unbalances.

Summarizing it is possible to suggest that Solaris and Monarch need to be monitored for N, whilst Cabernet Cortis and Solaris for K to avoid sub optimal nutrient status. Bronner, Johanniter, Monarch, and Regent need to be supplied with sufficient $\mathrm{Mg}$, especially in years where rainfall is concentrated in the spring months. Therefore, for this cation, early foliar treatments should be recommended, in years with similar conditions.

Furtherly, it is important to ensure Zn supply when Bronner, Monarch, Regent, and Solaris are cultivated; a specific control of manganese levels should also be scheduled above all when cold and wet spring happen.

\section{References}

1. S. Pedò, M. Bottura, D. Porro. L'Informatore Agrario, 4, 42-46 (2019)

2. S. Pedò, M. Bottura, D. Porro. BIO Web of Conferences, 1302004 (2019).

3. O. Failla, G. Stringari, D. Porro, A. Scienza. In: M.A.C. Fragoso and M.L. Beusichem (eds.), Optimization of Plant Nutrition. Kluwers, Netherlands. p.37-41 (1993).

4. H. Marschner. In: Mineral Nutrition of Higher Plants. Second edition. Academic Press, London, UK: 116130 (1995).

5. D. Porro. G. Stringari, O. Failla, A. Scienza. Acta Hort, 564, 413-420 (2001). 